Review began 09/26/2021 Review ended 10/05/2021 Published 10/07/2021

๑) Copyright 2021 Mir et al. This is an open access article distributed under the terms of the Creative Commons Attribution License CC-BY 4.0. which permits unrestricted use, distribution, and reproduction in any medium, provided the original author and source are credited.

\section{A Case Report of Acute Transient Encephalopathy Following a Trans-esophageal Echocardiography}

\author{
Wasey Ali Yadullahi Mir ${ }^{1}$, Dhan B. Shrestha ${ }^{2}$, Vijay Ketan Reddy ${ }^{1}$, Suman Gaire ${ }^{3}$, Larissa Verda ${ }^{1}$ \\ 1. Department of Internal Medicine, Mount Sinai Hospital, Chicago, USA 2. Department of Medicine, Mount Sinai \\ Hospital, Chicago, USA 3. Department of Emergency Medicine, Palpa Hospital, Palpa, NPL
}

Corresponding author: Dhan B. Shrestha, medhan75@gmail.com

\begin{abstract}
Methemoglobinemia is caused due to an increase in methemoglobin in the blood, impairing oxygen transfer to tissues. Acquired methemoglobinemia is caused by various drugs like local anesthetics, antibiotics, nitrates, nitrites, and food additives. We present a case of a 73-year-old male who presented with cyanosis, altered mental status, and hypoxia following transesophageal echocardiography. Arterial blood gas analysis revealed methemoglobinemia. He had been given topical lidocaine and benzocaine spray before the procedure. He improved after the administration of methylene blue. The case highlights the importance of considering methemoglobinemia in patients presenting with cyanosis, altered mental status, and hypoxia after endoscopic procedures.
\end{abstract}

Categories: Anesthesiology, Internal Medicine, Hematology

Keywords: benzocaine, local anesthetics, methemoglobinemia, transesophageal echocardiography, lidocaine, cyanosis, hypoxia

\section{Introduction}

Methemoglobinemia is a rare condition of the blood associated with an increase in the proportion of methemoglobin, which affects the oxygen-carrying capacity of the blood. There are two types of methemoglobinemia, congenital and acquired. Congenital/inherited methemoglobinemia is caused by a genetic deficiency of an enzyme cytochrome B5 reductase or a hemoglobin protein defect (Hemoglobin M disease). The acquired form is associated with exposure to certain chemicals/medications like local anesthetics (benzocaine, prilocaine, lidocaine); antibiotics (dapsone, sulfonamides, chloroquine); nitrates (salts, nitroglycerin); nitrites (nitroprusside, nitrous oxide, food additives); nitrobenzene (used in lubricating oils, dyes), and many others $[1,2]$.

We present a case of methemoglobinemia following topical lidocaine and benzocaine spray for transesophageal echocardiography.

\section{Case Presentation}

A 73-year-old African American male presented to the hospital for lower back pain and symptoms of urinary tract infection and a chronic great toe wound with discharge. His history was significant for type 2 diabetes mellitus, hypertension, and coronary artery disease, post-stenting five years ago.

His blood culture collected at the time of hospital admission was positive for Streptococcus dysgalactiae. Other significant laboratory findings at the time of admission were a complete blood count of $17000 / \mathrm{mm}^{3}$, hemoglobin of $13 \mathrm{gm} / \mathrm{dL}$, the random blood sugar of $212 \mathrm{mg} / \mathrm{dL}$, blood urea/creatinine of $13 / 1.37 \mathrm{mg} / \mathrm{dL}$, and raised inflammatory markers (erythrocyte sedimentation rate [ESR]: $140 \mathrm{~mm} / \mathrm{hr}$, creactive protein [CRP]: $299 \mathrm{mg} / \mathrm{L}$ ). The patient was started on vancomycin and cefepime based on his blood culture report. Right hallux wound incision and drainage had Streptococcus dysgalactiae, Staphylococcus capre, and methicillin-resistant Staphylococcus aureus, then MRI confirmed right hallux osteomyelitis. He underwent right hallux amputation. Further workup showed that patient had a spinal abscess, which developed due to the seeding of bacteria from his toe infection. He underwent bilateral laminectomy and decompression with drainage of the abscess.

A transthoracic echocardiogram done to rule out infective endocarditis showed no vegetations. Due to high suspicion of infective endocarditis, transesophageal echocardiography was also performed using benzocaine $20 \%$ spray to the back of the throat before procedure initiation. In addition, the patient was given $1 \mathrm{mg}$ of midazolam and $25 \mathrm{mcg}$ of fentanyl for pre-procedure sedation. Within minutes after the procedure, the patient was cyanotic, diaphoretic, confused, and developed a facial droop on the operating table. Code Stroke was called. Vitals were blood pressure 99/56, heart rate 106, respiratory rate 30 , saturating $76 \%$ on room air. He was started on supplemental $\mathrm{O} 2$ with a non-rebreather mask. He was intermittently bagged with saturation improving to $85 \%$ on $100 \%$ O2 with on and off improvement in mental status and facial droop resolved. The decision was made not to intubate the patient, and an arterial blood gas analysis (ABG) 
was done, which showed chocolate-brown colored blood and a partial pressure of oxygen (PaO2) of 185 mmHg with 70\% methemoglobin (ABG-pH/PaO2/PaCO2/HCO3: 7.48/185/37/27.6). The patient was immediately given $1 \mathrm{mg} / \mathrm{kg}$ of methylene blue and transferred to the intensive care unit (ICU). Within 15 minutes, the patient was improving, with improved cyanosis, mental status, and improving diaphoresis. One hour repeat ABG showed methemoglobin levels of 31. Poison control was called, and they recommended methemoglobin levels less than 30, with a goal of less than 20, and resolution of symptoms. In the following hour, the attending toxicologist recommended re-dosing with another $1 \mathrm{mg} / \mathrm{kg}$ for a total of $2 \mathrm{mg} / \mathrm{kg}(100$ $\mathrm{mg}$ ) methylene blue for persistently elevated methemoglobin levels greater than the goal level. The repeat $A B G$ after the second dosing of methylene blue showed methemoglobin levels less than 10 . The toxicologist recommended following the methemoglobin levels on Arco oximetry ABG. His final ABG showed a methemoglobin level of 2.6 and saturation maintained with oxygen supplementation via nasal cannula. The patient was discharged the next day to a rehabilitation center with antibiotics.

We report this case to draw attention to rare circumstances of methemoglobinemia following the use of local anesthetics. This may not be considered and missed during code scenarios due to uncommon encounters, a general lack of awareness, and limited availability of standard co-oximetry for an accurate diagnosis.

\section{Discussion}

A transesophageal echocardiogram (TEE) is used for better visualization of posterior cardiac structures not clearly visualized by transthoracic echocardiography. It is a safe procedure, and only a few significant complications have been reported. The major complications include esophageal perforation, gastrointestinal bleeding, pharyngeal hematoma, and methemoglobinemia [3-5].

Methemoglobinemia following TEE is due to local anesthetic spray use. In a retrospective study for all adverse events following benzocaine use, 132 of 198 cases (66.7\%) were related to methemoglobinemia, which involved 107 serious events $(81.1 \%)$ and even two deaths (1.5\%). More than $90 \%$ of these cases were related to benzocaine spray use. Most of these cases of benzocaine-related methemoglobinemia happened in the inpatient setting following procedures needing endoscopy of any kind [6]. The incidence of methemoglobinemia was $0.067 \%$ in a series of over 28,000 TEEs performed in a center [7].

Risk factors for developing methemoglobinemia following medication use depends on several factors which affect the drug concentration (both levels and time taken to clear) in the blood: elderly, glucose 6-phosphate dehydrogenase (G6PD) deficiency, high doses, prolonged use, concomitant use of multiple oxidant drugs (lidocaine + benzocaine), route of administration, concomitant problems (heart, lung, liver, kidney), sepsis, and shock. Methemoglobinemia can present early or might take time to manifest after drug exposure (ranging from one to 10 hours). This is because some of the above medications need to transform into toxic metabolites before symptoms manifest [1].

Clinical presentation depends on the severity of methemoglobinemia. According to the increasing level of methemoglobin in the blood, the symptoms are cyanosis, chocolate-colored blood, headache, anxiety, tachycardia, dizziness, changes in mental status, tachypnea, and syncope arrhythmias, seizures, coma, and death [2]. Our patient presented with altered mental status, cyanosis, and hypoxia following TEE. Refractory hypoxemia, cyanosis, and chocolate-colored blood following any procedure or after the use of topical anesthetics are highly suggestive of methemoglobinemia.

The gold standard for diagnosis remains co-oximetry, but some blood gas analyzers give methemoglobin levels as well. Traditional pulse oximetry is unreliable in diagnosing methemoglobinemia. It cannot distinguish oxyhemoglobin from abnormal hemoglobin like methemoglobin, sulfhemoglobin, and carboxyhemoglobin which bind and carry oxygen to varying extents but do not release it to the tissues $[2,8]$. Oxygen saturation gap (difference between oxygen saturation measured by pulse oximeter and saturations by blood gas analysis) $>5 \%$ indicates the presence of abnormal hemoglobin [9].

Treatment of severe methemoglobinemia with methylene blue is done only if the patient is symptomatic or methemoglobin $>30 \%[6]$. Care is needed with methylene blue as it is known to cause hemolysis in toxic doses or G6PD-deficient individuals [10-12]. However, most patients respond rapidly to the treatment, as seen in our patient.

\section{Conclusions}

Topical anesthetic use is associated with methemoglobinemia. In addition, episodes of methemoglobinemia are reported after TEE. Therefore, it is crucial to keep methemoglobinemia very high in differential in cases of cyanosis, altered mental status, and hypoxia after application of local anesthetics. In addition, it is imperative to differentiate methemoglobinemia from other complications of TEE in such patients.

\section{Additional Information}

\section{Disclosures}


Human subjects: Consent was obtained or waived by all participants in this study. Conflicts of interest: In compliance with the ICMJE uniform disclosure form, all authors declare the following: Payment/services info: All authors have declared that no financial support was received from any organization for the submitted work. Financial relationships: All authors have declared that they have no financial relationships at present or within the previous three years with any organizations that might have an interest in the submitted work. Other relationships: All authors have declared that there are no other relationships or activities that could appear to have influenced the submitted work.

\section{Acknowledgements}

We want to acknowledge our patient without whom this report would not have been possible. Additionally, we would like to thank all the treating healthcare personnel involved in patient care.

\section{References}

1. Alanazi MQ: Drugs may be induced methemoglobinemia . J Hematol Thromboemb Dis. 2017, 6:10.4172/2329-8790.1000270

2. Ludlow JT, Wilkerson RG, Nappe TM: Methemoglobinemia. StatPearls Publishing, Treasure Island; 2021.

3. Min JK, Spencer KT, Furlong KT, DeCara JM, Sugeng L, Ward RP, Lang RM: Clinical features of complications from transesophageal echocardiography: a single-center case series of 10,000 consecutive examinations. J Am Soc Echocardiogr. 2005, 18:925-9. 10.1016/j.echo.2005.01.034

4. Spier BJ, Larue SJ, Teelin TC, et al.: Review of complications in a series of patients with known gastroesophageal varices undergoing transesophageal echocardiography. J Am Soc Echocardiogr. 2009, 22:396400. 10.1016/j.echo.2009.01.002

5. Saphir JR, Cooper JA, Kerbavez RJ, Larson SF, Schiller NB: Upper airway obstruction after transesophageal echocardiography. J Am Soc Echocardiogr. 1997, 10:977-8. 10.1016/S0894-7317(97)80015-6

6. Moore TJ, Walsh CS, Cohen MR: Reported adverse event cases of methemoglobinemia associated with benzocaine products. Arch Intern Med. 2004, 164:1192-6. 10.1001/archinte.164.11.1192

7. Kane GC, Hoehn SM, Behrenbeck TR, Mulvagh SL: Benzocaine-induced methemoglobinemia based on the Mayo Clinic experience from 28478 transesophageal echocardiograms: incidence, outcomes, and predisposing factors. Arch Intern Med. 2007, 167:1977-82. 10.1001/archinte.167.18.1977

8. Nappe TM, Pacelli AM, Katz K: An atypical case of methemoglobinemia due to self-administered benzocaine. Case Rep Emerg Med. 2015, 2015:670979. 10.1155/2015/670979

9. Akhtar J, Johnston BD, Krenzelok EP: Mind the gap. J Emerg Med. 2007, 33:131-2. 10.1016/j.jemermed.2006.11.016

10. Harvey JW, Keitt AS: Studies of the efficacy and potential hazards of methylene blue therapy in anilineinduced methaemoglobinaemia. Br J Haematol. 1983, 54:29-41. 10.1111/j.1365-2141.1983.tb02064.x

11. Rosen PJ, Johnson C, McGehee WG, Beutler E: Failure of methylene blue treatment in toxic methemoglobinemia. Association with glucose-6-phosphate dehydrogenase deficiency. Ann Intern Med. 1971, 75:83-6. 10.7326/0003-4819-75-1-83

12. Khan M, Paul S, Farooq S, Oo TH, Ramshesh P, Jain N: Rasburicase-induced methemoglobinemia in a patient with glucose-6-phosphate dehydrogenase deficiency. Curr Drug Saf. 2017, 12:13-8. $10.2174 / 1574886312666170111151246$ 